\title{
Collaborative Planning and Design of High-rise Buildings Based on BIM and GIS
}

\author{
Ouyang Fangxin ${ }^{1}$, Du Xiaochu ${ }^{2,3}$
}

(1. School of Civil Engineering and Architecture of Wuhan Polytechnic University, Wuhan, Hubei, 430023; 2. School of Resources and Environment of Hubei University, Wuhan, Hubei, 430062; 3. Hubei Provincial Key Laboratory for Regional Development and Environmental Response, Wuhan, Hubei, 430062)

Key words: high-rise buildings; BIM; GIS; collaborative planning and design

Abstract: There are many factors involved in the planning and design of high-rise buildings. This paper has analyzed requirements related to the planning and design of high-rise buildings and put forward the strategy of combining BIM with GIS technology in its design. Such a collaborative planning and design approach can not only improve work efficiency, but also lay a solid foundation for subsequent production and management.

With the accelerated urbanization in our country, plenty of people have been concentrated in cities, which has made the conflict between human beings and land more prominent and also led to the continuous increase in the number of high-rise buildings. To improve the level of information-based planning and design for high-rise buildings is the prerequisite for the construction of smart cities. Currently, BIM (Building Information Modeling) has been widely applied in architecture at home and abroad ${ }^{[1]}$, which has also been used in the construction management of high-rise buildings. ${ }^{[2-3]}$ On the other hand, in the planning and design of high-rise buildings, we should not only take characteristics of buildings themselves into consideration, but also closely integrate them with their geographical features, thus applying an approach of a combination of BIM with GIS technology. In order to better integrate the two technologies, we should strive to achieve the interoperability of data collected through the two systems. Some researchers have also conducted corresponding studies in this respect. ${ }^{[4-6]}$ In addition, the integration of BIM and GIS technology has already been carried out in areas like smart cities, regional planning and site analysis, etc. ${ }^{[7-10]}$.

In this paper, the issue of collaborative planning and design of high-rise buildings based on BIM and GIS is discussed. Based on the analysis of factors related to the planning and design of high-rise buildings, the structural and functional characteristics of BIM and GIS have been combined to create the collaborative planning and design strategy of high-rise buildings based on BIM and GIS so as to improve the level of intelligence in planning and management.

\section{Factors with an Impact on the Planning and Design of High-rise Buildings}

Although the application of high-rise buildings can greatly improve the conservation and intensive use of resources, which will bring significant social and economic benefits, compared with low-rise and multi-storied buildings, there are also features like vulnerability to external effecting elements, complicated structure and difficulty in construction, etc. which requires more factors to be taken into consideration during the planning and design. 


\section{External Effecting Elements}

(1) Elements of Natural Environment

Geological Conditions Since high-rise buildings have a large dead weight and a high demand for pile foundation, the geological conditions of construction site should be taken into consideration during the design, which means we should obtain sufficient geological data, including stratigraphic structure, soil properties, soil freezing depth, distribution of underground caves and burial conditions of groundwater, etc.

Topographic features Terrain features should also be taken into consideration in the design of high-rise buildings, including different types of landforms like mountains, hills and plains with varied shapes of strip, compact and irregular form, which will affect not only the floor height and shape of high-rise buildings, but also their design scheme and construction technology.

Climatic conditions Climatic conditions mainly include light, temperature, humidity, wind force, wind direction, atmospheric pressure and precipitation, etc., all of which will also have a major impact on the design of high-rise buildings. For example, during the design, we should pay constant attention to leaving appropriate spacing between high-rise buildings so as to ensure that low-story households could have at least an average one-hour sunshine per day in winter; we should also adopt different wall materials and wall thickness according to varied temperatures in different regions.

(2) Socio-economic Elements

Functional Orientation of Buildings Determining the function of high-rise buildings is a prerequisite in their planning and design, and the determination should also take into full account of relevant socio-economic factors. For example, in order to determine whether a high-rise building is used for commercial, residential or office purpose, it is necessary to consider factors like local traffic conditions, economic development, residential structure, culture and customs, etc.

Urban Planning Requirements High-rise buildings, especially those skyscrapers, are very high in general, which upon completion may exceed the control height of the area stipulated by urban planning department or may affect the overall landscape of the city's skyline. Therefore, the planning and design must be conducted within the requirements of urban planning department so as to create a harmonious and unified urban landscape with reasonable floor height and elaborated design of the top of high-rise buildings.

Urban Supporting Facilities The design of high-rise buildings should also take their surrounding buildings, roads, green spaces, other public service facilities like electricity, telecommunications, gas, water supply network and so on into account

\section{Key Points in the Design of High-rise Buildings}

The design of high-rise buildings should pay greater and closer attention to the design of the buildings themselves, whose main content and requirements in design are shown in Figure 1.

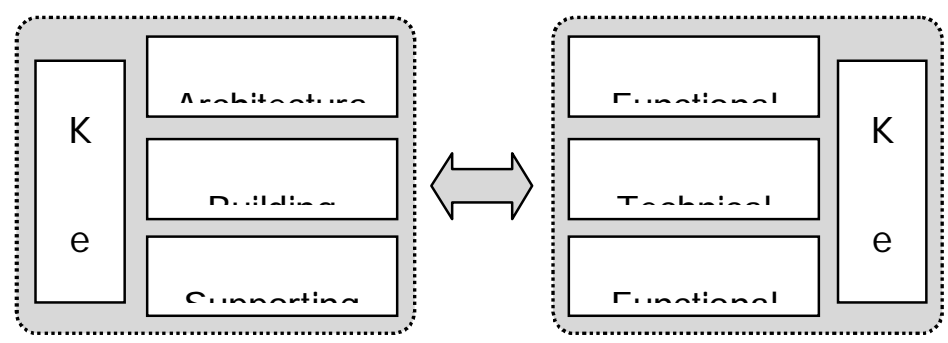

Figure 1 Key Points and Requirements in the Design of High-rise Buildings

(1) Architectural Layout 
The design of high-rise buildings should pay attention to the following aspects in the building layout design. First of all, in overall plane layout, pay attention to fire safety and the placement of fire escape. Specifically, enhance capacity of evacuation for population and vehicles and expand parking areas. Secondly, strengthen the standard design of multi-layer plane layout to meet the vertical and technical design requirements. Thirdly, ensure the rational layout of vertical traffic, such as the location, quantity, specification of stairs and elevators and so on. Fourthly, pay attention to the renovation of buildings. It is important to choose refurbishing materials and technical schemes according to the deformation of buildings. Fifthly, pay attention to the style and modeling effect. It is important to integrate buildings themselves with their surrounding environment to create a perfect landscape.

(2) Building Structure

High rise buildings with large size and huge height have a higher demand for their seismic capacity and wind-resistant capacity. Therefore, it is necessary to pay attention to strengthening their performance in these two aspects. Secondly, pay attention to the overall design of high-rise buildings, such as maintaining reasonable height-width ratio to ensure the stability of the buildings; and also maintaining the symmetry between the quality and rigidity of the buildings to ensure their well-proportioned shape. Thirdly, pay attention to the structural design of deformed joints to avoid any unnecessary damage caused by temperature, earthquake or land subsidence, etc. In addition, issues related to design scheme and construction technology based on geological conditions and dead weight of buildings and other factors need to be considered.

(3) Supporting Facilities

The heating and water supply and drainage systems in high-rise buildings will be under much greater pressure than multi-storied buildings, for which reasonable design scheme should be adopted. Secondly, high-rise buildings have their own unique way in the design of fire prevention and smoke prevention. Thirdly, high-rise buildings have a complicated power supply system with a huge system load, so great importance should be attached to the design of different electrical circuit.

\section{Integration of BIM and GIS}

\section{BIM and GIS}

BIM (Building Information Modeling) refers to a technology that has been applied to digitally analyze, simulate and visualize the planning, design, construction and management process of buildings. BIM will combine the graphic information and attribute information of buildings to create a relevant information model, which can help improve the quality and efficiency of the design, construction and management of buildings through data analysis and 3D visualization. BIM has been widely applied in architectural design and management both at home and abroad.

GIS (Geographic Information System) is a computer system that collects, stores, manages, analyzes and displays geographic information. It mainly stores geo-spatial data and attribute data with spatial analysis and visualization being its core functions. GIS methods and technologies have developed rapidly in recent years, which have been widely used in almost all industries and sectors related to spatial information, including cartography, urban planning, disaster management and vehicle navigation, etc.

From the description of objects, BIM is to deliver a description and modeling of the internal structure of buildings, which reflects the shape, size and spatial relationship of buildings themselves and their internal components, and establishes relevant models for analysis and management. In contrast, GIS mainly aims at the geographical environment, reflecting the spatial and non-spatial 
quantitative characteristics of buildings, including their location, size, and the spatial relationship of their external environment, between themselves and between buildings and other objects. Therefore, BIM is a micro-model built for the interior of a building, while GIS is a macro-model built for a cluster of buildings inside an area.

As mentioned above, in the design of high-rise buildings, we should not only take buildings themselves into consideration, but also conduct an analysis over their geographical environment and socioeconomic environment, thus, it is imperative to integrate BIM with GIS.

\section{Integration of BIM and GIS}

The main difficulty in the integration of BIM and GIS lies in the difference of data formats, which requires data docking between the two systems. IFC (Industry Foundation Classes) is the standard data format of BIM, which is supported by most mainstream BIM software such as Revit, Microstation and Tekla. Meanwhile, CityGML (City Geography Markup Language) is a data format for three-dimensional city modeling in 3D GIS, which can accomplish tasks like spatial data mining, facility management and topic queries.

Currently, some researchers have put forward conversion methods between these two data formats ${ }^{[4-5]}$, and domestic hypergraph GIS software also supports the exchange format of IFC model. With the further development of the research and the wide application of these software, data exchange between BIM and GIS will become more convenient.

You can achieve the integration between BIM and GIS through data exchange between them with the process as shown in Figure 2.

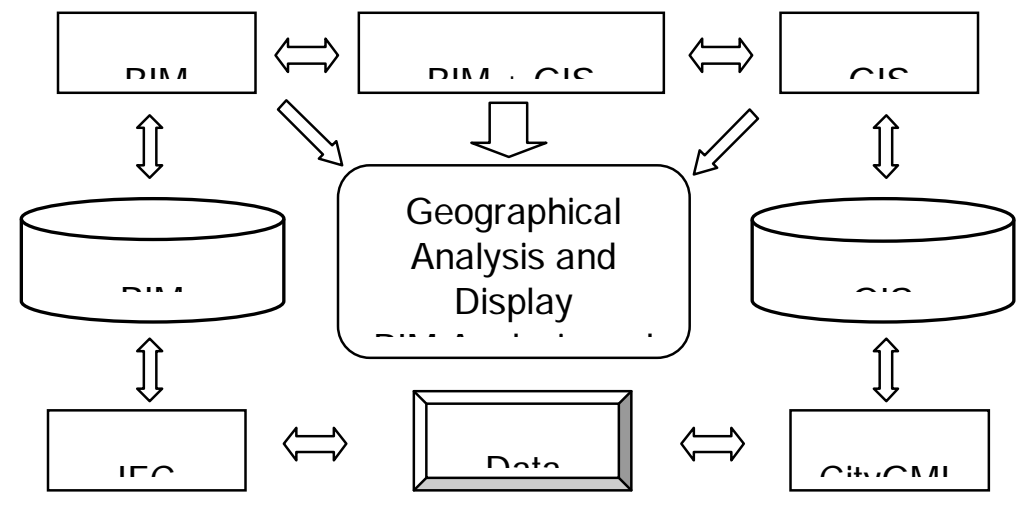

Figure 2 data exchange and fusion between BIM and GIS

Figure 2 BIM and GIS data exchange and integration

\section{Collaborative Design Strategy for High-rise Buildings Based on BIM and GIS}

\section{Data and Personnel}

There are mainly two types of data involved in the design of high-rise buildings, one is related to the geographical data which constitutes a GIS database, and the other is the building data which forms a BIM database. Geographic data primarily includes data related to geological, topographic, climatic, economic, urban development and public facilities conditions, as shown in Table 1. 
Table 1 Geographical Data Related to the Design of High-rise Buildings

\begin{tabular}{|c|c|}
\hline $\begin{array}{c}\text { Data } \\
\text { Classification }\end{array}$ & Data Name \\
\hline Geological Data & $\begin{array}{c}\text { Stratigraphic Structure, Soil Properties, Soil Freezing Depth, } \\
\text { Distribution of Groundwater and Karst Caves }\end{array}$ \\
\hline Terrain Data & $\begin{array}{l}\text { Topographic Map, Slope and Aspect Map and Plot Distribution } \\
\text { Map }\end{array}$ \\
\hline Climatic Data & $\begin{array}{l}\text { Light, Temperature, Humidity, Wind Direction and Wind Force } \\
\text { and Precipitation }\end{array}$ \\
\hline Economic Data & $\begin{array}{c}\text { Road Traffic, Income and Consumption Level, GDP, } \\
\text { Population, Consumer Behavior }\end{array}$ \\
\hline $\begin{array}{c}\text { Urban } \\
\text { Development }\end{array}$ & $\begin{array}{l}\text { Urban Planning, Distribution of Architectural Complex, } \\
\text { Building Density, Building Height and Building Distribution }\end{array}$ \\
\hline Public Facilities & $\begin{array}{c}\text { Roads, Green Spaces, Electricity, Telecommunications, Gas, } \\
\text { Water Supply Networks }\end{array}$ \\
\hline
\end{tabular}

Building data can be divided into the following types. First of all, data related to building materials, including the specifications, performance, strength, density, fire-resistant strength, etc. of various building materials, which is the basic data of building data. Second, basic norms in the design of high-rise buildings, such as code for fire protection design of buildings, buckles, design value of base bearing capacity, allowable deflection for deformation, parameters for height and seismic capacity and wind pressure height variation coefficient, etc. Third, formula for the calculation of various building index, such as formula for the calculation of building area density, floor area ratio, building density and load design value, etc. In addition, relevant parameters related to different building structures, such as reinforced concrete structures, steel structures, masonry structures and frame structures, etc.

The composition of personnel involved in the design of high-rise buildings is also very complicated, including architects, structural engineers, mechanical and electrical engineers, budget engineers and geological experts. The design of high-rise buildings is accomplished through the concerted efforts and cooperation among all personnel.

\section{Design Process}

The design of high-rise buildings based on BIM and GIS can be divided into the following steps (as shown in Figure 3).

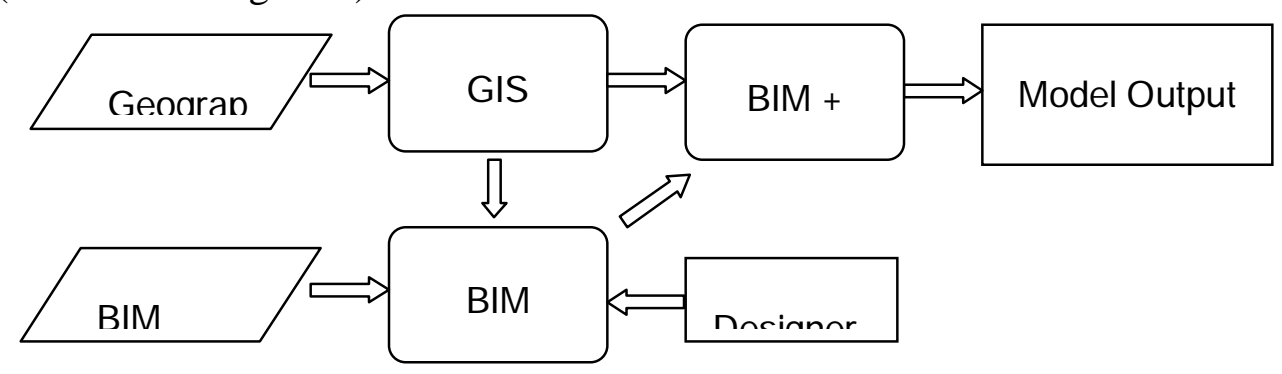

Figure 3 BIM- and GIS-based Collaborative Design Process

(1) Geographic Data Analysis

In the design of high-rise buildings, we must first analyze relevant geographic data to determine the basic parameters of buildings. For example, in order to determine the height and height-width ratio of high-rise buildings, it is necessary to conduct a comprehensive analysis over the geological conditions of the construction area, including its wind force and wind direction, light 
conditions and skyline, etc.; in order to determine the structure of deformed joints of high-rise buildings, it is also imperative to analyze data like temperature, wind force and land subsidence in the construction area besides from the characteristics of building materials themselves; in order to select the right building materials for energy-efficient buildings, it is also vital to comprehensively analyze local climatic conditions, etc. Geographic data analysis can be conducted with ArcGIS, Supermap or other software.

(2) BIM Modeling

BIM modeling is the core process in the design of high-rise buildings. During this process, designers of various fields will work together to establish a BIM model for high-rise buildings according to the results obtained through a comprehensive analysis over the geographical data and BIM data. The BIM of each component can be established first, such as building BIM, structure BIM, water supply and drainage BIM, HVAC BIM, electrical BIM and fire prevention BIM, etc., and then comprehensive collision tests and relevant experimental verification should be carried out to determine the final scheme. During the design of BIM, BIM and GIS analysis methods can also be applied in the analysis and verification period in line with different requirements. For example, during the design of general plane layout, it is necessary to determine the function and volume of high-rise buildings according to the results of analysis over relevant socioeconomic data, road traffic data, terrain data and other geological data so as to deliver a reasonable planning and design scheme for the functional layout of building such as fire prevention design, indoor passage design and ancillary facilities design, etc.

(3) Model Output and Visualization

At this stage, a BIM information model for high-rise buildings has completed which requires relevant model and data to be exported. Output can be achieved in the form of chart or table, and the design model, drawings and data can be printed out. On the other hand, 3D virtual simulation technology can be applied to visualize the design results. This visualization is a full range of visualization which can display internal details of high-rise buildings such as top beams and columns, as well as show various functional areas of buildings, even more so for the exterior environment of buildings and the overall landscape of their associated areas.

\section{Conclusion}

The design of high-rise buildings needs to take into account a variety of factors which also requires to be analyzed and visualized from both macro and micro perspectives. This problem can be well addressed through the combination of BIM and GIS. This paper has analyzed factors with an impact on the design of high-rise buildings, put forward the idea of collaborative design of high-rise buildings based on BIM and GIS, discussed the feasibility of such a method from the perspective of data fusion and studied the specific strategies in implementing this method.

\section{Reference}

[1] Liu Bo, Liu Wei, Research on the Current Application and Obstacles of BIM in Domestic Architecture Industry, Architectural Economy, 2015,36 (9): 20-23.

[2] Che Liancheng, Research on the Construction Safety Management for BIM-based High-rise Buildings, Value Engineering, 2016,27 (26): 60-62.

[3] Wang Lin, Huangpu Dongmei and Jia Zhen, The Influence of BIM Technology on Fire Fighting Rescue for High-rise Buildings, Construction Technology, 2015,44 (18): 49-52. 
[4] Zhu Liang, Deng Fei, Research on BIM and 3DGIS Integration Method Based on Semantic Mapping, Journal of Geomatics, 2016,41 (3): 16-19.

[5] Zhao Xia, Tang Shengjun, Liu Mingwei, etc., Conversion Method from Semantic Constraint RVT Model to CityGML Model, Geographic Information World, 2015 (2): 15-20.

[6] Li Li, Deng Xueyuan, The Construction and Application of BIM Database Based on IFC Standards, Sichuan Building Science Research, 2013,39 (3): 296-301.

[7] Deng Shaolun, Research on the Construction Plan and Evaluation of Coordinated Regional Planning Based on BIM-GIS Technology, Architectural Economy, 2016,37 (6): 41-44.

[8] Chen Leiming, Exploration of BIM- and GIS-based Smart Cities, Civil Engineering and Information Technology, 2016,8 (6): 91-95.

[9] Zhou Wen, Li Qiannan, Pan Liangbo, etc., Research and Realization of BIM-and GIS-based Intelligent Management Platform for Utility Tunnels, Geographic Information World, 2017,24 (3): 97-100.

[10] Zhang Lin, Application and Research of Site Analysis Based on BIM and GIS Technology, Sichuan Architectural Science Research, 2014, 40 (5): 327-329. 